\title{
Mix de recursos para el manejo de problemáticas adolescentes
}

Norma Ibarra López y Lorena Lizbeth Torres Guzmán

\section{Resumen}

$\mathrm{E}$ 1 docente en su práctica requiere ir más allá del aula y de un programa de estudios; es necesario que conozca las problemáticas a las que se enfrentan sus estudiantes para enfocar de manera efectiva la enseñanza. El presente artículo muestra la recomendación de algunos libros y una serie de televisión que pueden ser consultados por el profesor, con el fin de analizar dichas problemáticas y promover nuevas estrategias en su docencia para abarcarlas.

Palabras clave: recursos didácticos, problemáticas educativas, adolescencia.

La práctica docente es una labor multidimensional, donde dominar la disciplina impartida no es suficiente. De acuerdo con el Modelo Educativo Institucional de la UAA (2007), los docentes son profesionales que además “[...] cuentan con conocimiento pedagógico, curricular, didáctico, y del contexto social" (p. 8). Por tanto, es importante que sean conscientes de los principales retos o problemáticas a las que se enfrentan sus estudiantes según el nivel educativo en el cual se desempeñan.

En educación media superior (EMS), de acuerdo con Hernández, Trejo y Hernández (2018), uno de dichos retos es que el profesor sea capaz de participar en "una estrategia nacional de acompañamiento [...] que les permita tener información de primera mano sobre la educación socioemocional y resolver dudas sobre su puesta en práctica" (p. 96). En este sentido, se sugiere al docente la consulta de los siguientes recursos, seleccionados por su potencial para contribuir al desarrollo de la esfera socioemocional de los estudiantes del nivel educativo referido.

\section{Programa de educación emocional para} adolescentes. De la emoción al sentido

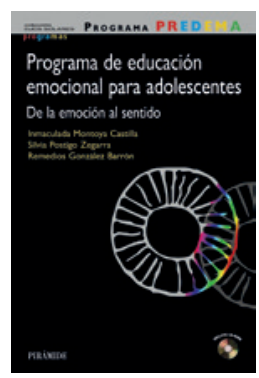

Inmaculada Montoya Castilla, 2016

Editorial Pirámide

Este libro es ideal para profesores que buscan aprender sobre sí mismos y sus emociones, de forma que posteriormente puedan enseñar a los adolescentes el valor de éstas en su vida. La autora presenta un programa, que consta de una sugerencia práctica para el docente en torno a las emociones en el aula, además de testimonios de aprendizaje de jóvenes que participaron en este programa. Con esto se pretende que el profesor no sólo reflexione sobre la educación emocional, sino que conozca estrategias para implementarlas en el aula.

\section{Educar en lenguaje positivo. El poder de las} palabras habitadas

Luis Castellanos, 2017

Ediciones Paidós

El autor realiza una reflexión acerca del valor y la influencia que pueden tener las palabras en nuestras vidas. Presenta estrategias para comprender y favorecer la relación que existe entre el lenguaje

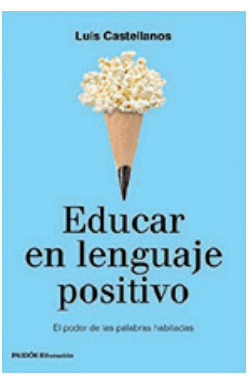
y el área emocional, partes esenciales a tomar en cuenta en el contexto educativo, tanto por docentes como por estudiantes. 


\section{Aprendizaje emocionante}

\begin{tabular}{|c|}
\hline 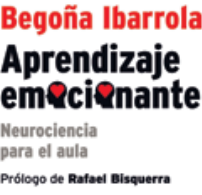 \\
\hline$\equiv$ \\
\hline
\end{tabular}

Ediciones SM
Begoña Ibarrola, 2013

Este libro muestra una investigación que permite acercar al docente a la comprensión del funcionamiento del cerebro, como una guía para transformar sus estrategias educativas y optimizar el aprendizaje en sus estudiantes. Se analiza cómo influyen las emociones en la fijación de los recuerdos, en la motivación, en la conducta de los alumnos y en su proceso de aprendizaje, con el objetivo de optimizar la práctica pedagógica y provocar en el alumnado una activación que garantice un adecuado desarrollo socioemocional y mejor rendimiento escolar.

Respecto a otras problemáticas del adolescente de EMS, en el ámbito personal y de salud existen conductas o factores de riesgo con las que el docente deberá estar familiarizado. De acuerdo con la Organización Mundial de la Salud (oms, 2018), algunos de dichos factores son: embarazos precoces, enfermedades de transmisión sexual, depresión, violencia, alcoholismo, drogadicción, tabaquismo, etcétera. En el ámbito académico, según el Instituto Nacional para la Evaluación de la Educación (INEE, $\mathrm{s} / \mathrm{f}$ ), existe un alto índice de deserción escolar en nuestro país, debido a diversas causas o problemáticas pedagógicas, entre las cuales se destaca que:

Un número importante de docentes no logra interesar a los jóvenes en las clases [...] Los temas de comunicación, trato y vínculo afectivo con los jóvenes no aparecen adecuadamente en los programas de formación continua de los docentes de EMS, [y] los docentes $\mathrm{y}$ directivos manifiestan dificultades para comunicarse y entender a sus estudiantes.
Un ejemplo excelente sobre cómo abarcar dichas problemáticas es la siguiente serie, la cual, si bien se contextualiza dentro de la cultura española, abarca las mismas cuestiones que presentan de forma recurrente los adolescentes de nuestro país:

\section{Merlí, 2015}

\section{Serie Española}

Disponible en Netflix

Merlí es un profesor de filosofía que invita a los jóvenes a reflexionar no sólo sobre las diversas teorías y enfoques de los más grandes filósofos, sino a practicar las distintas ideologías en su vida diaria. Durante las tres temporadas, Merlí interactúa con

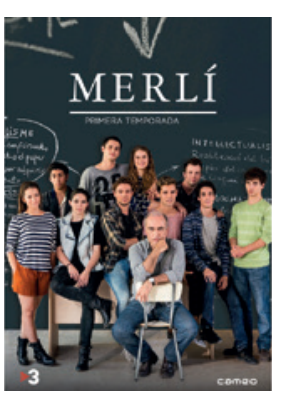
diferentes personajes que enfrentan situaciones como: padres ausentes, enfermedades, etiquetas sociales y escolares, rezagos educativos, indiferencia y falta de motivación, drogadicción, embarazos adolescentes, entre otras. Este docente hace lo posible por implementar su estilo en cada estrategia, y aunque en varias ocasiones sus métodos van más allá de los ideales institucionales convencionales, logra conectar con el grupo al grado de crear una red de apoyo escolar y familiar. La serie resalta la importancia de la vocación docente, la cual trasciende de estar un par de horas frente a grupo, y abre la reflexión sobre la necesidad de la comunicación, la confianza y la incorporación de distintas estrategias, enfoques y recursos didácticos en la enseñanza.

\section{Fuentes de consulta}

Hernández, M., Trejo, Y. y Hernández, M. (2018). El desarrollo de habilidades socioemocionales de los jóvenes en el contexto educativo. Revista RED, Revista de Evaluación para Docentes y Directivos, (3), 88-97. Recuperado de: https://www.inee.edu.mx/images/stories/2018/Red9/Red09.pdf.

Instituto Nacional para la Evaluación de la Educación (INEE, s/f). Directrices para mejorar la permanencia escolar en la educación media superior. Recuperado de: http://publicaciones.inee.edu.mx/buscadorPub/P2/A/334/ P2A334.pdf.

Organización Mundial de la Salud (2018). Adolescentes: riesgos para la salud y soluciones. Recuperado de: https:// www.who.int/es/news-room/fact-sheets/detail/adolescents-health-risks-and-solutions.

UAA (2007). Modelo Educativo Institucional. Correo Universitario, séptima época, (15). [Primera reimpresión] 29 de mayo de 2015. México: UAA. Recuperado de: https://bit.ly/2OrlYxX. 